\title{
AVALIAÇÃO FÍSICA, QUÍMICA E MICROBIOLÓGICAS DE SALAMES CASEIROS EM DIFERENTES TEMPERATURA DE ARMAZENAMENTO
}

\author{
FARIAS,Glaucia Vasques de ${ }^{1}$ \\ HONORATO, Claucia Aparecida ${ }^{1}$ \\ DEBOLETO, Sandriele Goes de Campos ${ }^{1}$ \\ CHAMAA, Andrea Ribeiro Luz ${ }^{2}$
}

\begin{abstract}
RESUMO: Os produtos embutidos são muito apreciados, independente dos costumes, dentre eles estão os salames que consiste em carne picada e condimentada, classificados como produto fermentado cru, seco ou semiseco e não-emulsionado, com baixo teor de umidade e presença de ácido láctico.o salame caseiro não possui garantia de BPF e apresenta variáveis que vão determinar o tempo para consumo seguro. A temperatura regula o crescimento microbiano delimitando o tempo de consumo, mas o local de estocagem também influencia na multiplicação microbiana levando à perdas econômicas como inviabilizando o consumo. A higiene dos produtos alimentícios são de suam importância para segurança alimentar da população. Destaca-se nestes setores o comercio informal de produtos alimentícios que são comercializados, que não possuem fiscalização de controle de qualidade em nenhuma das etapas de fabricação e comercialização. Estes alimentos apresentam maior chance de sofrerem alterações físicas, químicas e microbiológicas que comprometem sua qualidade. Neste contexto as escassas as informações referentes a salame caseiro e o seu tempo e local de armazenamento este trabalho tem como objetivo avaliar a característica físico-química e microbiológica de salames caseiros submetidos em distintos tempos e locais de armazenamento. Foram adquiridos 24 salames caseiros. Um conjunto de 12 amostras formou a unidade que ficou armazenada na geladeira e um conjunto de 12 amostras formou a unidade que ficou a temperatura ambiente. As amostras foram analisados os parâmetros no momento inicial, 7 dias, 15 dias e 21 dias, nos distintos locais de armazenamento, quanto perda de peso, as análises químicas de teor de umidade, proteína, lipídios e matéria mineral e isolamento de Staphylococcus, Salmonella e Coliformes a $45^{\circ} \mathrm{C}$. Os resultados foram avaliados em um delineamento inteiramente casualisado (DIC) com dois tratamentos (duas situações de armazenamento - geladeira e ambiente) com doze repetições. Os resultados obtidos neste trabalho informam que estes produtos estão aptos para o consumo humano, segundo o padrão exigido pela vigilância sanitária (ANVISA), e que a temperatura de armazenamento não interfere na qualidade do produto.
\end{abstract}

Palavras-chaves: Agente microbiano. Segurança alimentar. Temperatura.

\section{PHYSICAL, CHEMICAL AND MICROBIOLOGICAL EVALUATION OF HOMEMADE SALAMES IN DIFFERENT STORAGE TEMPERATURES}

\begin{abstract}
SUMMARY: The built-in products are highly appreciated, regardless of customs, among them salami consisting of minced and seasoned meat, classified as raw, dry or semi-dry and non-emulsified fermented product with low moisture content and presence of lactic acid the homemade salami has no BPF guarantee and presents variables that will determine the time for safe consumption. The temperature regulates the microbial growth delimiting the time of consumption, but the place of storage also influences in the microbial multiplication leading to the economic losses as unfeasible the consumption. The hygiene of food products is of paramount importance for the food security of the population. Of note in these sectors is the informal trade in food products that are marketed, which do not have quality control inspection in any of the manufacturing and marketing stages. These foods are more likely to undergo physical, chemical and microbiological changes that compromise their quality. In this context the scarce information about salami and its time and place of storage this work aims to evaluate the physical-chemical and microbiological characteristics of homemade salami submitted at different times and storage locations. 24 homemade salamis were
\end{abstract}

\footnotetext{
${ }^{1}$ Universidade Federal da Grande Dourados, Faculdade de Ciências Agrarias, Rodovia Dourados/Itahum, Km 12 Unidade II | Caixa Postal: 364, | CEP: 79.804-970

${ }^{2}$ Faculdade de Ciências Biológicas e da Saúde, Nutrição, Centro Universitário da Grande Dourados - UNIGRAN, Rua Balbina de Matos, 2121, Dourados - Mato Grosso do Sul - MS, CEP: 79.824-900.
} 
purchased. A set of 12 samples formed the unit that was stored in the refrigerator and a set of 12 samples formed the unit that remained at room temperature. The samples were analyzed at the initial time, 7 days, 15 days and 21 days, at the different storage sites, how much weight loss, chemical analyzes of moisture content, protein, lipids and mineral matter and isolation of Staphylococcus, Salmonella and Coliforms at $45^{\circ} \mathrm{C}$. The results were evaluated in a completely randomized design (DIC) with two treatments (two storage situations - refrigerator and environment) with twelve replicates. The results obtained in this work report that these products are suitable for human consumption, according to the standard required by sanitary surveillance (ANVISA), and that the storage temperature does not interfere with the quality of the product.

Keywords: Microbial agent. Food toxinfection. Temperature.

\section{INTRODUÇÃO}

No mercado atual, a produção de alimentos está cada vez mais voltada para a sua segurança e estabilidade, sem, contudo, deixar de atender às expectativas do consumidor quanto à qualidade sensorial. Salame é um embutido classificado como produto fermentado cru, seco ou semi-seco e não-emulsionado (ORDÓÑEZ 2005). É preparado com a mistura de carnes moídas, com variações quanto à composição e adição de condimentos e aditivos responsáveis pelas variações de salames produzidos no país. Diferencia-se dos demais embutidos pelo baixo teor de umidade e pela presença de ácido lático, que confere sabor característico (NASSU, 2002).

Os produtos fermentados secos mantêm as características adquiridas durante as fases de processamento e maturação, pela ação de vários fatores que agem em sinergismo. Além de estarem associados às características sensoriais, alguns deles contribuem também para inibição de patógenos e de deterioradores (SCHEID et al., 2003).

A conservação de produtos de origem animal embutido, por um período longo recomenda-se a embalagem a vácuo e boas práticas de fabricação (BPF) (NASSU et al., 2002). Contudo o salame caseiro além de não haver garantias de BPF apresenta outras variáveis que interferem na sua conservação como uso limitado de conservantes. A associação dessas variáveis ao tipo de estocagem e conservação pode determinar o tempo que este produto pode ser consumido com segurança (LISTON, 2008).

A temperatura é um dos fatores que regula o crescimento microbiano nos alimentos e consequentemente o tempo de viabilidade do produto. A vida de um produto é a duração de tempo durante a qual ele funciona adequadamente (ALBUQUERQUE; ROCHA, 2011). Um dos fatores determinantes para conservação de alimentos é o local e a temperatura de armazenamento que podem propiciar a multiplicação microbiana, acarretando perdas econômicas como alterações sensoriais dos alimentos e inviabilizando seu consumo (LISTON, 2008).

Um dos principais fatores que causam a deterioração e contaminação dos alimentos está relacionado com a higiene do manipulador e dos alimentos, que podem vir a causar uma série de doenças alimentares (PEREIRA et al. 2002, p.147-150). Na avaliação de salames "do tipo 
alemão" comercializados nas feiras livres da cidade de Pelotas, RS foi constatado que estes estão livres de contaminação por Salmonella e Coliformes a $45^{\circ} \mathrm{C}$, no entanto há presença de Staphylococcus coagulase o que evidencia um perigo real de transmissão de intoxicação alimentar por meio da toxina estafilocócica (BAIRROS et al., 2006)

Com o objetivo de proteger a saúde dos consumidores, foi estabelecida através da ANVISA a RDC nº12 (BRASIL, 2001) que compõe os padrões microbiológicos para grupos de alimentos, visando sua qualidade higiênica sanitária. O salame pertence ao grupo dos produtos cárneos maturados, possuindo padrão de coliforme a $45^{\circ} \mathrm{C}$ - tolerância para amostra indicativa de $10^{3} / \mathrm{g}$, Staphlococcus sp coagulase positiva - tolerância para amostra indicativa de $5 \times 10^{3} / \mathrm{g}$.

Um dos fatores determinantes para conservação de alimentos é o local de estocagem. Neste local a temperatura é o fator determinante para a multiplicação microbiana, portanto a falta de controle da temperatura de conservação dos alimentos perecíveis acarreta não só importantes perdas econômicas, como alterações sensoriais dos alimentos e, principalmente, danos à saúde do consumidor (LISTON, 2008). O emprego da refrigeração não tem ação de eliminar os microrganismos, portanto, o alimento em condições precárias de sanidade, não poderá ser melhorado, mas sim, o que se pode conseguir é retardar o crescimento bacteriano impedindo que certas DTA's ocorram (EVANGELISTA, 1987).

Neste contexto as escassas as informações referentes a salame caseiro e o seu tempo e local de armazenamento este trabalho tem como objetivo avaliar a característica físico-química e microbiológica de salames caseiros submetidos em distintos tempos e locais de armazenamento.

\section{MATERIAL E MÉTODO}

Os salames foram adquiridos em uma empresa de comercialização de salames caseiros de grande destaque em volume de vendas na cidade de Fátima do Sul/MS segundo dados da associação comercial da cidade. Foram adquiridos 24 salames caseiros, um dia após sua fabricação no local pré estabelecido (grande destaque em volume de vendas em Fátima do $\mathrm{Sul} / \mathrm{MS})$.

Os salames foram levados ao laboratório em suas embalagens originais onde ocorreu a desinfecção das embalagens com hipoclorito de sódio (200ppm). Um conjunto de 12 amostras formou a unidade que ficou armazenada na geladeira e um conjunto de 12 amostras formou a unidade que ficou a temperatura ambiente.

As amostras foram avaliadas no momento de chegada ao laboratório caracterizando o tempo inicial e posteriormente em intervalos de sete dias. Com isso foram analisados os parâmetros no momento inicial, 7 dias, 15 dias e 21 dias, nos distintos locais de armazenamento. 
Para a coleta primeiramente realizou-se às análises físicas. Posteriormente os salames foram abertos em uma capela de fluxo laminar e divididos em duas sub-amostrask, com material previamente esterelizado. Uma amostra em torno de $25 \mathrm{~g}$ foi colocada em tubo falcom (50ml), para posterior homogenização em água destilada para analise microbiologica. E o restante foi utilizado para as análises químicas (A.O.A. C, 2000).

Os salames foram pesados no dia zero e armazenados, e após cada tempo de armazenagem (7 dias), estes foram novamente pesados e, pela diferença entre o peso no inicio e no final do tempo

$$
\mathrm{PP}=\left[\frac{\text { pesoinicial - pesofinal }}{\text { pesofinal }}\right]
$$

de armazenagem foi obtida a perda de peso em gramas. Este valor foi dividido pelo peso do salame no início do armazenamento, gerando os dados de perda de peso, em porcentagem (SANTOS et al., 2000).

As análises químicas de teor de umidade, proteína, lipídios e matéria mineral foram realizadas seguindo a metodologia AOAC (2000), todas as mostras foram realizadas em triplicata.

Para as análises microbiológicas foram analisados os salames de cada situações de armazenamento (ambiente e geladeira) nos tempos de armazenamento (inicial, 7, 15 e 21 dias). Com base nas recomendações da ANVISA (Agência Nacional de Vigilância Sanitária), se realizou o cultivo para isolamento de Staphylococcus, Salmonella e Coliformes a $45^{\circ} \mathrm{C}$. As metodologias para isolamento e identificação das respectivas bactérias foram realizadas de acordo com Jay et al. (2005).

Os resultados foram avaliados em um delineamento inteiramente casualisado (DIC) com dois tratamentos (duas situações de armazenamento - geladeira e ambiente) com doze repetições. Os dados foram analisados em esquema de parcela subdividida cujo tratamento principal é o local de estocagem e o tratamento secundário as avaliações ao longo do tempo (quatro avaliações). As análises de variância (ANOVA) e as médias foram comparadas pelo testes de Tukey $(\mathrm{p}<0,05)$, pelo programa Statistical Analysis System (SAS Intitule Inc., version 6.12, 1999).

\section{RESULTADO E DISCUSSÃO}

O comercio informal foi escolhido para aquisição dos salames uma vez que há maior possibilidade de contaminação devido as condições insatisfatória do local que são alocados os produtos para comercialização, como vias públicas e expostos ao ambiente, ao alcance de contaminantes e possíveis vetores de enfermidades DTA. 
Os embutidos artesanais saõ poucos testados quanto a viabilidade sanitária (Salvatori, 2003). Através da metodologia para análises microbiológicas recomendada pela ANVISA, observou-se que para Staphylococus coagulase positiva, Salmonella e Coliformes a $45^{\circ} \mathrm{C}$ não houve isolamento em nenhuma amostra. (Tabela 1).

Tabela 1. Avaliação microbiológica de salames caseiros armazenados em diferentes temperaturas (ambiente e geladeira).

\begin{tabular}{|c|c|c|c|}
\hline \multirow[b]{2}{*}{ Avaliações } & \multirow[b]{2}{*}{ INICIAL } & \multicolumn{2}{|c|}{ Armazenamento } \\
\hline & & AMBIENTE & GELADEIRA \\
\hline Staphylococus coagulase positiva & Ausência & Ausência & Ausência \\
\hline Salmonella sp & Ausência & Ausência & Ausência \\
\hline Coliformes Fecais (NMP.g-1) & Ausência & Ausência & Ausência \\
\hline Coliformes Totais (NMP.g-1) & Ausência & Ausência & Ausência \\
\hline
\end{tabular}

A Divisão Nacionalde Vigilância Sanitária, órgão do Ministérioda Saúde, ResoluçãoRDC $\mathrm{n}^{\mathrm{o}}$ 12, de 2 de Janeiro de 2001, Anexo I,estabelece como Padrões Microbiológicos

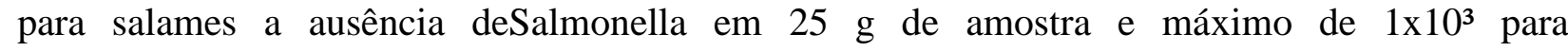
coliformes $\mathrm{a} 45^{\circ} \mathrm{C}$ (VIEIRA;MENDONÇA, 2005). Em virtude dos resultados obtidos, pode-se dizer que as amostras analisadas neste trabalho não foram veículos de microrganismos patogênicos causadores de doenças alimentares, tais como Salmonelose e Gastroenterite por $E$. coli. A ausência de contaminação observada na maioria das amostras (80\%) indica um procedimento adequado no processamento, armazenamento, transporte e manipulação dos alimentos estudados, bem como a higienização de uma maneira geral.

Tabela 2. Composição bromatológica de salames caseiros armazenados em diferentes temperaturas.

Armazenamento

\begin{tabular}{|c|c|c|c|}
\hline Avaliações & INICIAL & AMBIENTE & GELADEIRA \\
\hline Matéria Seca (\%) & $56,92 \pm 0,50 b$ & $72,82 \pm 0,63 \mathrm{a}$ & $68,62 \pm 0,24 a b$ \\
\hline Umidade (\%) & $43,08 \pm$ & $27,18 \pm$ & $31,38 \pm$ \\
\hline Proteína bruta (\%) & $31,51 \pm$ & $38,22 \pm$ & $34,55 \pm 0,539$ \\
\hline Lipídeos (\%) & $39,21 \pm 0,67 b$ & $43,88 \pm 2,29 a$ & $39,96 \pm 2,06 a b$ \\
\hline Matéria mineral (\%) & $7,39 \pm$ & $8,23 \pm$ & $6,7 \pm$ \\
\hline Matéria orgânica (\%) & $82,608 \pm$ & $91,77 \pm$ & $93,3 \pm$ \\
\hline Energia bruta $\left(\mathrm{Kcal} \mathrm{kg}^{-1}\right)$ & $6102,69 \pm 165,48$ & $6058,20 \pm 240,90$ & $6105,80 \pm 206,96$ \\
\hline
\end{tabular}


Observou-se que o local de armazenamento influenciou de forma efetiva o peso do salame durante o armazenamento (Figura 1A). Os salames armazenados em temperatura ambiente apresentaram queda de peso sendo está adequada a uma equação linear (Figura 1 B). Os salames armazenados em geladeira perderam peso de forma menos drástica mantendo suas características de aparência agradável e esta perda seguiu o comportamento quadrático (Figura 1B).

Figura 1. Relação entre umidade e matéria seca (A) de salames caseiros armazenados em diferentes temperaturas (ambiente e geladeira) e (B) Analise de regressão da perda de peso de salames Letra diferente reporta diferença estatística pelo teste de Tukey $(\mathrm{P}<0,05)$. Valores expressos em média (5) \pm desvio padrão.

A

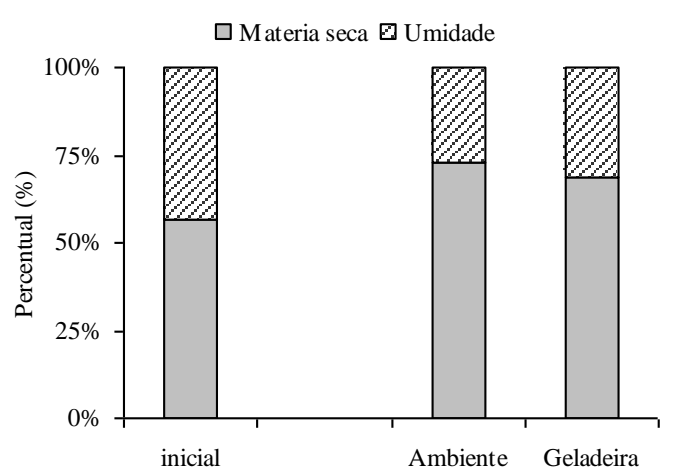

B

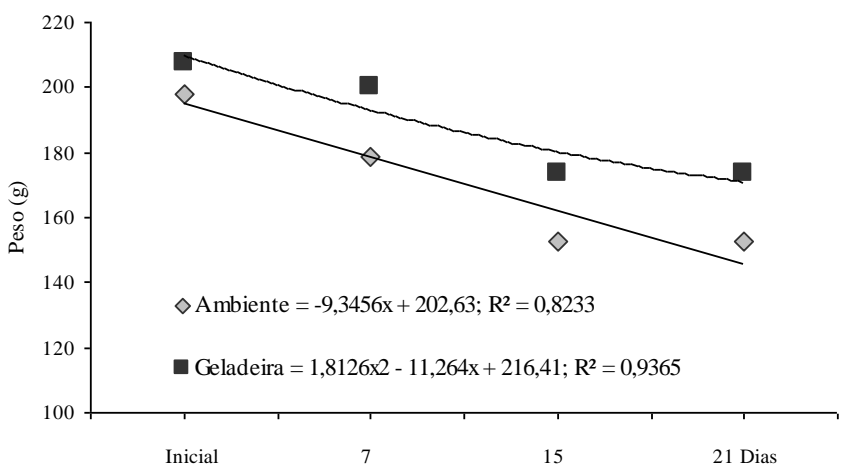

A variação nas propriedades físicas de produtos alimentícios armazenados sob diferentes condições de armazenamento foram reportadas por (KAPUCI ; HONORATO, 2012). Enfatiza-se que em ambientes sem controle de temperatura as mudanças são maiores no entanto, se o produto foi elaborado em condições higiênico sanitária, não a mudanças na qualidade sanitária do produto.

\section{CONCLUSÃO}

A higiene dos produtos alimentícios são de suma importância para segurança alimentar da população. Destaca-se nestes setores o comercio informal de produtos alimentícios que são comercializados, que não possuem fiscalização de controle de qualidade em nenhuma das etapas de fabricação e comercialização. Estes alimentos apresentam maior chance de sofrerem alterações físicas, químicas e microbiológicas que comprometem sua qualidade. Os resultados obtidos neste trabalho informam que estes produtos estão aptos para o consumo humano, segundo o padrão exigido pela vigilância sanitária (ANVISA), e que a temperatura de armazenamento não interfere na qualidade do produto. 


\section{REFERÊNCIAS}

ALBUQUERQUE, C.J.M.; ROCHA, J.G.C. Estimação do tempo de prateleira de um produto perecível a partir de dados de inspeção. Disponível em:

http://www.abepro.org.br/biblioteca/ENEGEP2001_TR25_0661.pdf, Acesso em 01 de junho de 2011.

ALENCAR, N. Manual de produção de embutidos, CPT, Viçosa, p. 34, 1996.

ASSOCIATION OF OFFICIAL ANALYTICAL CHEMISTS (AOAC). Official Methods of Analysis, 17th edn. AOAC, Gaithersburg, MD, USA, 2000.

BACKES, A.M. Desenvolvimento de produto cárneo fermentado adicionado de óleo de canola, 2011. 128f. Dissertação (Mestrado em Ciência e Tecnologia dos Alimentos) Universidade Federal de Santa Maria (UFSM, RS), Santa Maria, 2011.

BAIRROS, V.B.Aet al. análise microbiológica de salame vendido em feira livre, 2006. Disponível em: http://www.ufpel.edu.br/cic/2006/arquivos/CB_01387.rtf, Acesso em 01 de maio de 2011.

BANZATO, D. A.; KRONKA, S. N. Experimentação agrícola. 2.ed. Jaboticabal: FUNEP, p. 247, 1992.

BRASIL. Instrução Normativa n. 22, de 31 de julho de 2000. Anexo V: Regulamento Técnico de Identidade e Qualidade de Salame. Publicada no Diário Oficial da União de 01/08/00.

CARIONI, F.O.et al. Uso de culturas iniciadoras para a elaboração de um embutido à base de carne de pato (Cairina moschata). Ciência e Tecnologia de Alimentos, n²1. São Paulo: Varela, p. 34-38, 2004.

CICHOSKI, A.J. ZIS,L.C.;FRANCESCHETTO, Características físico-químicas e microbiológicas da superfície do salame tipo italiano contendo solução de lactato de potássio. Ciência e tecnologia Alimentar, v.29 n 3,Campinas, 2009.

EVAngeliStA, J., Tecnologia de Alimentos. São Paulo: Atheneu, p. 660. 1987.

FAGUNDES, H.; OLIVEIRA, C. A. F. Infecções intramamárias causadas por Staphylococcus aureus e suas implicações em saúde pública. Ciência Rural, nº 34, p. 1315-1320. 2004.

FAO. FOOD AND AGRICULTURE ORGANIZATION OF THE UNITED NATIONS. Food Quality and Safety Systems: a training manual on food hygiene and the hazard analysis and critical control point (HACCP) system. Roma, p. 232. 1998.

GALLI, F. Os embutidos: como fabricá-los. Revista Nacional da Carne, 17(194): 14-27, 1993.

CAPUCI, K. ; HONORATO, C. A. Efeito da temperatura de estocagem na qualidade do mel. Revista de Ciências Exatas e da Terra UNIGRAN, v1, n.1, 2012.

IAL - Instituto Adolfo Lutz. Normas Analíticas do Instituto Adolfo Lutz. Métodos físicoquímicos para análise de alimentos, 4 ed. São Paulo: IAL, 2008, p. 1000. Versão eletrônica 
LISTON, P. H. avaliação da temperatura na rede de frio em mercados no município de pinhais PR. 2008. 86 f. Monografia (pós-graduação "Lato Sensu" em Higiene e Inspeção de Produtos de Origem Animal) - UCB, Curitiba, 2008. Disponível em: http://www.qualittas.com.br/documentos/Avaliacao\%20da\%20Temperatura\%20\%20Paulo\%20Henrique\%20Linston.PDF. Acesso em 01 de junho de 2011.

MACEDO, R.E.F.et al. Desenvolvimento de embutido fermentado por Lactobacillus probióticos: caracteristicas de qualidade. Ciência e Tecnologia de Alimentos, v. 28, n.3, Campinas, 2008.

MAHONEY, M.; HENRIKSSON, A .The effect of processed meat and meat starter cultures on gastrointestinal colonization and virulence of Listeria monocytogenes in mice. International Journal of Food Microbiology, v.84, n. 3, p. 255-261, 2003.

MESQUITA, M. O.; DANIEL, A. P., SACCOL; A. L. F. Qualidade microbiológica no processamento do frango assado em unidade de alimentação e nutrição. Ciência e Tecnologia de Alimentos, nº 26, p. 198-203, 2006.

MIRALLES, M. C.; FLORES, J.; PREZ-MARTINEZ, G. Biochemical tests for the NOVAK, F. R.; ALMEIDA, J. A. G. Teste alternativo para detecção de coliformes em leite humano ordenhado. Jornal de Pediatria. 2002, 78, p.193-196, p. 232-239, 2006.

MISSAGLIA, A.P., Segurança alimentar, Embrapa-VII Seminário de Aves e Suínos -AveSui regiões 2007 Avicultura, Belo Horizonte - MG, 2007.

NASSU, R. T.; BESERRA, F.J.; GONÇALVES, L.A.G. Processo Agroindustrial: Obtenção de Embutido Fermentado Tipo Salame de Carne de Caprinos. Comunicado Técnico 74, Embrapa Agroindústria Tropical, Fortaleza-CE, 2002.

ORDÓÑEZ, J. A. et al. Tecnologia de alimentos: alimentos de origem animal. Porto Alegre: Artmed, 2005.

PELEGRINI, L.F.V. et al . Elaboração de embutido fermentado tipo salame utilizando carne de ovelhas de descarte. Ciência e tecnologia de alimentos, v.28, Campinas, 2008.

PEREIRA, M.P.D. et al .Avaliação quantitativa da microbiota bacteriana contaminante em açougues no município de Soropédia como indicador de qualidade higiênico-sanitario.Revista Universidade Rural.Série Ciências da Vida, Rio de Janeiro, v. 22, n.2, p. 147-150, 2002. PHILIPPI, S.T. Nutrição e técnica dietética. Barueri, SP: Manole, 2006.

PRADO, C.S.et al. Atividade antimicrobiana de bactérias lácticas de embutidos curados frente à Listeria monocytogenes. Arquivo Brasileiro de Medicina Veterinária e Zootecnia, $\mathrm{n}^{\circ}$ 52, p. 417-423, 2000.

SANTA, O.R.D. Avaliação da qualidade de salames artesanais e seleção de culturas starter para a produção de salame tipo italiano. Curitiba, 2008.

SAKATE, R. I.et al. Quantificação de Listeria monocytogenes em salames fatiados embalados a vácuo, Archivos Latinoamericanos de Nutrición, v.53, n.2, Caracas, 2003. 
SANTOS, S.P.et al. Rendimento de carcaça e avaliação do método de salga úmida nos filés com e sem pele do pacu (piaractus mesopotamicus). In: $3^{\circ}$ Congresso Brasileiro de Produção de Peixes Nativos de Água Doce e $1^{\circ}$ Encontro de Piscicultores de Mato Grosso do Sul, 1., 2009, Cuiabá. Anais... Cuiabá: UFMT, 2009. CD ROM.

SAS (STATICAL ANALISYS SYSTEM). Institute, SAS/STAT. User's guide: sattistic. Cary, North Caroline: Versão 6.08, 4 ed., (2), p. 846. 1996.

SCHEID, G. Avaliação sensorial e físico-química de salame tipo italiano com diferentes concentrações de cravo-da-índia (Eugenia caryophyllus). Dissertação (Mestrado em Ciência e Tecnologia de Alimentos) Universidade Federal de Viçosa, Viçosa, 2001.

SILVA, N.; JUNQUEIRA, V. C. A.; SILVEIRA, N. F. A. Manual de métodos de análise microbiológica de alimentos. São Paulo: Varela, p. 317, 2001.

SILVEIRA, E.T.F.; ANDRADE, J. Aspectos tecnológicos de processamento e qualidade de embutidos fermentados. Campinas: FEA/UNICAMP, 1991.

STAMFORD, T.L.M.; SILVA, C. G. M., MOTA, R. A. Enterotoxigenicidade de Staphylococcus spp. isolados de leite in natura. Ciência e Tecnologia de Alimentos, n²6, p.41-45, 2006.

ANVISA. Agência Nacional de Vigilância Sanitária, Resolução RDC N ${ }^{\circ} 12$ de 2 de janeiro de 2001 REGULAMENTO TÉCNICO SOBRE PADRÕES MICROBIOLÓGICOS PARA ALIMENTOS

http://elegis.anvisa.gov.br/leisref/public/showAct.php?id=144; word=padr\%C3\%B5es\%20microb iol\%C3\%B3gicos acesso em 03 de outubro de 2006.

SALVATORI, R. U.; BESSA, M. C.; CARDOSO, M. R. I. Qualidade sanitária de embutidos coletados no mercado público central de Porto Alegre-RS. Ciência Rural, 2003, 33, p.771-773.

VIEIRA,E.N.R.; MENDONÇA,R.C.S.Embutidos fermentados e cultura starter:questão de qualidade.Rev Nac Carne, 15. ${ }^{\circ}$ Catálogo Brasileiro de Produtos ; Serviços,n.34, 2005. 